\title{
The Architect of the Medical Biology of Alcohol and Our Mentor: Memories of Dr. Ronald Thurman
}

\author{
YOSHIYUKI TAKEI
}

Department of Gastroenterology and Hepatology, Mie University Graduate School of Medicine, Mie, Japan

I started my studies in the laboratory of Dr. Ronald Thurman (Figure 1) at the University of North Carolina at Chapel Hill (UNC) on June 22, 1987. As an overseas student from the First Department of Internal Medicine of Osaka University, my senior, Dr. Harumasa Yoshihara, took me to meet the boss. I was a nervous student from Japan, but Dr. Thurman was friendly and put me at ease from our first meeting. "Are you ready for experiments?" he asked. Since then, Ron has had a huge influence on me as my mentor. I know that to go beyond your teacher is the highest form of repayment to your mentor, but Ron will always remain above me as a towering figure to look up to.

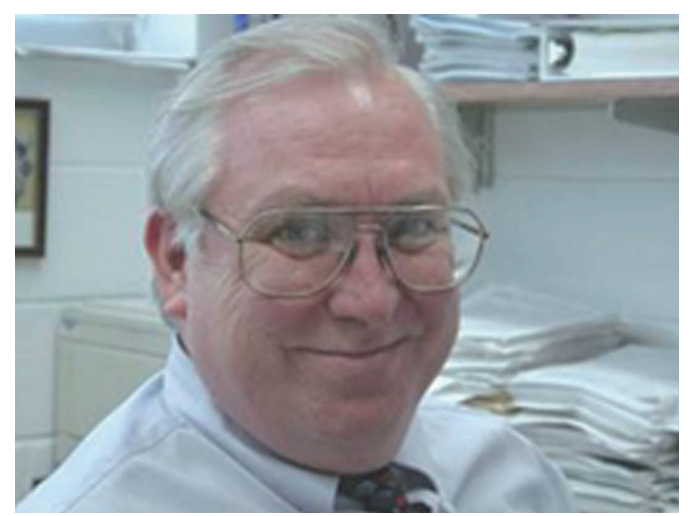

Figure 1 Ronald G. Thurman (11.25.1941-7.14.2001)

\section{Ron's background}

Born in Carbondale, Illinois, on November 25, 1941, Ron was an only child. Throughout his life, Ron kept a photograph of his parents standing beside their car, happily watching their young son take his faltering first steps. The photograph left a deep impression - the looks of the man who would go on to be a great professor were already discernible in the chubby face of the healthy youngster and the scene showed the economic might of America, which, in the period immediately after the beginning of the war with Japan, had already entered the age of mass car ownership. Ron graduated from the St. Louis College of Pharmacy in 1963 and earned his $\mathrm{PhD}$ from the University of Illinois, before setting out on his path as a postdoctoral researcher in the laboratory of Dr. Britton Chance at the Johnson Foundation of the University of Pennsylvania.

Dr. Nobuhiro Sato, who was my mentor throughout my time at the First Department of Internal Medicine of Osaka University and the Department of Gastroenterology of Juntendo University, was at the Johnson Foundation at the same time as Ron. Dr. Chance was a remarkable person, skilled in both science and sports. He was a renowned researcher, receiving the National Medal

Corresponding author: Yoshiyuki Takei

Department of Gastroenterology and Hepatology, Mie University Graduate School of Medicine, Mie, Japan

2-174 Edobashi Tsu, Mie 5148507, Japan

TEL: +81-59-231-5017 FAX: +81-059-231-5223 E-mail: ytakei@clin.medic.mie-u.ac.jp

〔Received Jan. 27, 2021] (Accepted Jan. 31, 2021〕

J-STAGE Advance published date: Jun. 14, 2021

Copyright (C) 2021 The Juntendo Medical Society. This is an open access article distributed under the terms of Creative Commons Attribution License (CC BY), which permits unrestricted use, distribution, and reproduction in any medium, provided the original source is properly credited. doi: 10.14789/jmj.JMJ21-P03 
of Science, the most prestigious prize for science in the US, for his achievements in the field of mitochondrial bioenergetics, and he also won a gold medal in sailing at the 1952 Helsinki Olympics. At that time, outstanding minds from the US and other countries, including Japan, were gathered together at the Britton Chance laboratory, and it is easy to imagine that they spurred each other on in a spirit of friendly rivalry. Ron moved to the laboratory of Dr. Roland Scholz at the University of Munich in 1969, where he studied the biochemistry of metabolism using perfused livers. He later returned to the Johnson Foundation as Assistant Professor and, in 1977, he was appointed Associate Professor in the Department of Pharmacology at UNC. Ron became a full professor in 1982 and, from 1988, he served as the Director of the Laboratory of Hepatobiology and Toxicology.

\section{Ron's achievements}

I have in front of me a copy of Ron's resume up to July 2001. According to this resume, during his lifetime, he published 406 original research papers and 814 reviews and book chapters. Looking at how the titles and journals changed over time provides a good understanding of how his academic career developed. He started as a pure biochemist, before turning his interests to explaining the mechanisms of hepatic pathophysiology and disorder through research into alcohol metabolism, finally arriving at a new concept of pathological connection, based around the gastrointestinal tract, the portal vein, and liver function.

\section{1) The historic controversy over alcohol metabolism}

Ron's first paper, which was on the metabolic system involving catalase, was published jointly with Dr. Chance in 1969 (Inhibition of catalase in perfused rat liver by sodium azide. Ann N Y Acad Sci 168: 348-353). Ron also worked on alcohol metabolism at Dr. the Scholz's laboratory, and published a paper on the involvement of catalase in alcohol metabolism in 1972. It was, therefore, only natural that he would direct his attention towards the role of catalase in ethanol metabolism.

Ethanol is metabolized into acetaldehyde, mainly by alcohol dehydrogenase (ADH) in the liver, but the contribution of other metabolic pathways increases at higher alcohol concentrations. Ron's group proposed the system of metabolism by catalase, located in the peroxisomes, as the main non-ADH system, whereas Charles Lieber et al. at Mount Sinai School of Medicine asserted that the microsomal ethanol oxidizing system (MEOS), chiefly involving cytochrome P450 (CYP2E1) located in the microsomes, was the predominant system. This inevitably developed into a dispute and it was eventually agreed that both sides would meet and perform experiments together to settle the matter. This epic joint experiment took place in 1973 at the Lieber laboratory in New York, and the late Dr. Hiromasa Ishii, who was an overseas student at the laboratory at that time, gave a full account of the circumstances surrounding the experiment in his book, Alcohol Medicine (IgakuShoin, 1981). It was a serious fight and the gloves were off, but the result was that the existence of MEOS was accepted and Ron's catalase theory was set aside. Catalase was unable to metabolize alcohol adequately in this experiment because the provision of the reaction rate-limiting hydrogen peroxide $\left(\mathrm{H}_{2} \mathrm{O}_{2}\right)$ substrate was insufficient to explain ethanol metabolism.

There was a sequel to this episode. Ron must have been greatly disappointed by the result, but he put together a team with Jeff Handler, a postdoctoral researcher, and continued to work tirelessly on the metabolic system involving catalase. The team put forward the counterargument that hydrogen peroxide was provided in large quantities as a result of the $\beta$-oxidation of fatty acids in the peroxisomes, and therefore could not self-limit ethanol metabolism; from the mid-1980s onward, they published numerous papers on this. Their findings indicated that if alcohol is ingested together with meals rich in fat, the involvement of the catalase system increases.

Alongside his work on the catalase system, Ron also made a major contribution to alcohol metabolism research through his discovery that the alcohol metabolic rate increases after acute alcohol administration, and he spent many years investigating the detailed mechanism of this phenomenon. Ron was a master of neologisms, and he named this phenomenon SIAM (Swift Increase in Alcohol Metabolism). He coined many other neologisms, such as SCOPE (Sublobular Compartmentation of Pharmacologic Events), which I will touch on later. 


\section{2) Intralobular microheterogeneity}

Within the hepatic lobule, the phases of metabolism, such as oxygen consumption, glycolysis, or gluconeogenesis, differ from the portal area towards the central vein. Thus, the metabolic functions of the liver overall are manifested through each sub-region having its own role to play in metabolism. Differences in the distribution of the enzyme systems responsible for various metabolic functions can be seen from zone 1 to zone 3 of the hepatic lobule, and this was understood to explain the heterogeneity of metabolism in the lobule. Ron's group responded to this "static hypothesis" by putting forward a novel idea: they suggested that metabolic processes are regulated by the local dynamism of substrates, such as partial pressures of oxygen. The technical breakthrough came with the development of a method for evaluating metabolic dynamics in extremely small areas by means of microlight guides using optical fibers and oxygen electrodes with ultra-fine tips $(50 \mu \mathrm{m})$. Moreover, combining the oxygen electrodes with Dr. Takakatsu Matsumura's stop-flow method allowed measurement of local oxygen consumption in different zones. For example, the team found that oxygen consumption by liver tissue was higher in the portal vein region than in the central vein region, but a momentary reversal of the two could be seen in the case of retrograde perfusion. This indicated that oxygen consumption by local tissue was dependent on the local oxygen concentration, rather than being determined by the anatomical location of the zone within the lobule. The first half of the 1980s was a period of tremendous progress for this project, and Ron published a review using the concept of SCOPE in Hepatology (1985; 5: 144-145) together with his friend and co-researcher, Fred Kauffman.

\section{3) Sinusoidal cell function and impairment of liver grafts}

I had worked on the pathogenic mechanism of alcoholic liver injury from the perspective of microcirculation during my time at Osaka University, so I naturally assumed that I would be doing work related to alcohol in Ron's laboratory. However, at that time, the laboratory was starting a liver transplantation project. The German postdoctoral researcher Ingo Marzi (currently Head of the
Department of Trauma, Hand, and Reconstructive Surgery at the University of Frankfurt) had single-handedly taken on experiments with rat liver transplantation models and, as Ingo was returning to Germany, a successor was needed to continue this project. Ron had told him to instruct someone in the technology for rat liver transplants, but Ingo was unwilling to teach someone unless they were an MD. Eventually, as I was the only MD enrolled in the laboratory, I was chosen for the task. So it turned out that I practiced microsurgery under Ingo and, as a result, I was able to become the world's first rat liver transplant physician.

The research theme we were given was to investigate the mechanisms of graft impairment in liver transplants and to devise countermeasures. Organs stored for a greater length of time before transplantation showed poorer engraftment and a greater probability of postoperative liver failure. Ron's laboratory was working on this project in collaboration with Prof. John Lemasters and we found, surprisingly, that a liver graft for transplantation that was immersed in a cold preservation solution for a long time and then examined in ultrafine detail using an electron microscope showed no obvious injury and evaluation of oxygen consumption in perfused livers revealed no major changes. Nonetheless, there were strict limits for liver storage time to ensure engraftment in liver transplantation models. At first, this phenomenon was incomprehensible and we were at a loss to explain it.

A clue to solving this mystery came from an unexpected quarter. By chance, we carried out electron microscopic examination of a perfused liver that had been used for the evaluation of metabolic dynamics - liver after reperfusion - and we obtained findings indicative of morphological damage to sinusoidal endothelial cells and activation of the macrophages resident in the liver (Kupffer cells). There were minimal changes in the hepatic parenchymal cells. These findings suggested that, as the storage time increases, the preliminary steps for regulation of impairment progression and changes in the sinusoidal endothelial and Kupffer cells first become apparent with reperfusion of the liver, and that the survival of the post-storage transplant may be determined by the degree of dysfunction and functional change of the sinusoidal cells, rather than the status of the hepatic parenchymal cells. 
Specifically, with storage for a long period, the Kupffer cells become primed so that, when the liver is reperfused, the activated Kupffer cells generate large quantities of cytokines. At the same time, endothelial cells are susceptible to ischemic injury and are all damaged immediately reperfusion occurs. The mediator for disorder from the Kupffer cells also intensifies endothelial cell dysfunction and failure of the hepatic sinusoid system causes perturbation of the hepatic microcirculation, which is linked to elimination of the graft.

This work had a number of implications. It was shown that dysfunction and functional modification of hepatic sinusoidal cells, during the process of organ storage and reperfusion, affected the immune and metabolic systems and that sinusoidal cells, which had always been seen as playing a bit part in the liver, suddenly became the leading players in hepatology. Hepatocytes are responsible for metabolism, but the movement that saw the process as possibly being under the control of sinusoidal cells was ablaze with enthusiasm and became the driving force for clarification of the importance of the hepatic sinusoidal cell system in major hepatic pathologies. Eventually, this led to a paradigm shift in the mechanisms of alcoholic liver injury.

\section{4) New mechanism of alcoholic liver injury:}

Pathological connection based around the gastrointestinal tract, the portal vein, and liver function

Ron's research returned once again to where it had begun, alcohol metabolism. I have already noted how the controversy surrounding MEOS and catalase had been relentless, but alcohol research subsequently entered a period of calm and, at the beginning of the 1990s, not even Ron's laboratory showed any conspicuous activity. However, the success of the liver transplant project had focused the gaze of Ron's research on the role of sinusoidal cells in alcoholic liver injury. At just this time, my successor, Dr. Taizo Hijioka, discovered the existence of voltage-dependent calcium channels in Kupffer cells (Mol Pharmacol 1992; 41: 435-440) and it became increasingly clear that cultured Kupffer cells showed activation through these channels when alcohol was added.

So, does chronic ethanol administration activate Kupffer cells? Are they involved in provoking hepatic disorder? As always, Ron's experimental approach started in a straightforward manner. He directed the laboratory staff to observe the effects of gadolinium, which removes Kupffer cells, on a model of alcoholic liver injury (French-Tsukamoto model). The results were positive - elimination of Kupffer cells spectacularly curbed hepatic disorder due to chronic alcohol loading. This work was immediately published in Hepatology (1994; 20: 453-460) by Dr. Yukito Adachi, who was an overseas student from the surgery department of Kyoto University at that time. This marked the start of a cascade of new evidence from the Thurman laboratory, paving the way for construction of a new paradigm, until Ron's death seven years later.

The laboratory immediately directed all its efforts towards clarifying the mechanism of activation of Kupffer cells during chronic alcohol loading. A series of disordered processes was revealed, in which alcohol consumption leads to changes in the gut microbiota, hyperpermeability of the intestine, and increased endotoxin (LPS) load on the liver. Activation of Kupffer cells then causes the overproduction of damaging or pro-inflammatory mediators, resulting in functional modification of sinusoidal endothelial cells and hepatic stellate cells. Ron used genetically modified mice and gene transfer techniques to clarify the roles of factors such as TNF $a$, ICAM1, NADPH oxidase, CD14, and TLR4; thinking about it now, he was leading research at a superhuman pace, almost as if he knew his time was limited. During this period, Ron published more than 50 related papers in elite journals such as the Journal of Clinical Investigation, Gastroenterology, Hepatology, the Journal of Immunology, and the FASEB Journal. It is worthy of special mention that many of these studies were the achievements of overseas students, including Dr. Kenichi Ikejima from Japan.

\section{A man of logic, feeling, and humor}

Ron was a remarkably deep person. W. Somerset Maugham wrote in his autobiography, The Summing $U_{p}$, "It has amazed me that the most incongruous traits should exist in the same person and for all that yield a plausible harmony," and looking from Maugham's point of view, Ron was an unequaled joker and a serious person. Perhaps it was that, while he had an uncommon mastery of irony, he also possessed old-fashioned sentiments of obliga- 
tion and compassion. He was always quick with a joke, and was certainly funny, but there was something in the depths of his eyes that did not laugh, and in spite of appearances, he was a serious man. He could be sharply critical of others but, on the other hand, he was kind and thoughtful towards his subordinates. Once, a particular postdoctoral researcher who got along very poorly with Ron stormed out of the laboratory. Even though that researcher was clearly in the wrong, Ron conscientiously wrote a letter of reference and helped him find his next post.

\section{Ron and his rivals}

Ron was in a never-ending state of conflict with his rival researchers, partly because of the many scientific innovations and partly because of his forthright speech and conduct. He remained an irreconcilable enemy of Charles Lieber throughout his life, over the subject of alcohol metabolism. He constantly crossed swords with many other scholars who were leaders in their fields, including conflict over intralobular microheterogeneity with Kurt Jungermann, who put forward the theory of the heterogeneity of intralobular enzyme distribution, and disagreement with the school of Dieter Häussinger, which emphasized the importance of $\mathrm{pH}$ gradient, as well as confrontation with Steven Strasberg over the mediators of sinusoidal endothelial cell disorder in hepatic transplants. In retrospect, these were bitter fights, but they were by no means unseemly brawls. They were always conducted earnestly and constructively in a spirit of intellectual inquiry and for the purpose of acquiring priority, and can be credited with leading to the development of new academic disciplines. I was once on the receiving end of some sharply-worded questioning at an international conference, but Ron told me there was nothing to fear. "You have to develop a rational argument that the other person cannot logically refute," he said, and this toughened me up. Ron also taught me that this is just what the word "formulate" describes.

\section{Memories of Chapel Hill}

As I previously noted, Ron moved to Chapel Hill in 1977. He was not very familiar with the area, but UNC is the oldest State University in the US, and Chapel Hill, known as the "Southern Part of
Heaven," was once selected by Newsweek as the most livable city in the US. As a result of this environment, Ron's work blossomed magnificently and he lived out his days nurturing a new generation of researchers. When I look back at my own time there as an overseas student, I feel a strong sense of nostalgia and remember all the pleasant times, but mixed with this is a feeling of emptiness, of a home that has lost its master.

\section{RGT Memorial Symposia}

Early in the morning of July 14, 2001, I was awoken by a telephone call from Dr. Akira Konno, an overseas student from Juntendo University then at Ron's laboratory. As it happens, this was my birthday, and this is no longer a happy day for me. Ron had not come to work, and when someone from the laboratory went to check on him, he was found dead of a heart attack in the hallway of his home. He was only 59. It was a dreadful shock.

I attended the memorial service at Chapel Hill, which was arranged by Dr. Nobuhiro Sato. Although I was meeting people from the laboratory and others connected to Ron for the first time in a while, I was there with a profound sense of grief.

On March 30 of the following year, 2002, a memorial symposium was held in honor of Ron, organized by Dr. Sato, his lifelong friend. The symposium was titled "Ronald G. Thurman Memorial Symposium: Alcohol, liver biology and toxicology," and was held at the Ariyama Noboru Memorial Hall of Juntendo University in Tokyo (Figure 2). In addition, the International Society for Biomedical Research on Alcoholism (ISBRA), of which Ron was the first president, held a memorial symposium in San Francisco. The Tokyo memorial symposium was attended by numerous authorities on hepatology, including Prof. David Brenner and Prof. John Lemasters from the US, and it was an exceedingly worthwhile event. An overview was published as a supplement to the Journal of Gastroenterology and Hepatology (2007; 22 Suppl 1). A memorial article was also published in Gastroenterology (121; 513: 2001), for which Ron had served as deputy editor.

\section{Ron's legacy}

The medical study of alcohol metabolism was Ron's life work and he made huge contributions to metabology, toxicology, and the clarification of 


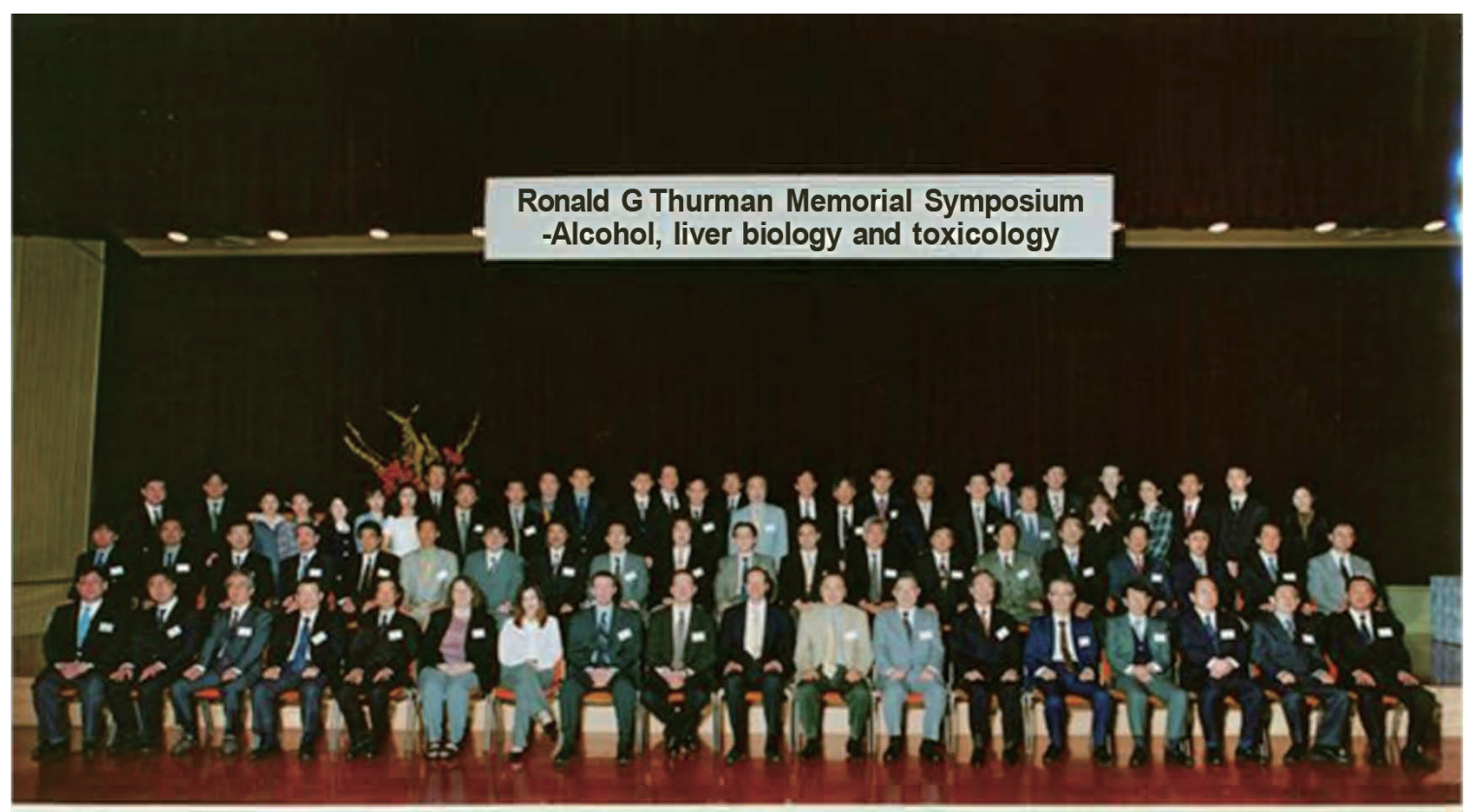

at Juntendo University, Tokyo March 30. 2002

Figure 2 Ronald G. Thurman Memorial Symposium: Alcohol, liver biology and toxicology at Juntendo University in 2002

mechanisms of hepatic disorder. His research results have had a profound influence not only on alcohol studies, but also in fields such as liver transplantation, viral hepatic injury, liver cirrhosis, carcinogenesis, and major hepatic pathologies such as nonalcoholic steatohepatitis (NASH).

In particular, his advocacy of the paradigm of the pathological connection based around the gastrointestinal tract, the portal vein, and liver function in alcoholic liver injury brought about new insights into the mechanisms of liver disorder and enticed researchers to the extensive world of intestinal microbiota. Following Ron's death, the scheme of Kupffer cell activation by LPS from the gastrointestinal tract and the resulting hepatic disorder and, moreover, the stimulation of an excessive immune response across the whole body, was shown to hold true also in NASH. The process in which lifestyle factors, such as a high-fat diet, bring about qualitative and quantitative changes in the intestinal bacteria and accelerate intraportal transfer has recently been widely recognized as metabolic endotoxemia. Alcoholic hepatitis and NASH have now been shown to have a shared basis and the understanding of this commonality has strengthened investigation into their pathologies and mechanisms and allowed them to stimulate new life and medical sciences. There is a movement towards the integration of these pathologies in the future into "metabolic steatohepatitis".

\section{I see little difference between my research goals and my role as an educator.}

This was Ron's motto, which he often repeated. He continued as follows:

"It is my aim to encourage graduate students to gather data sufficient for them to appreciate how exciting biomedical research can be."

Ron excelled as a researcher and educator. Fostering fully-fledged researchers by teaching beginners the basics of research, nurturing their ability to think logically, and opening their eyes to life sciences is a job that requires patience, and was undoubtedly one of Ron's major life works. A significant breakthrough in his final years (although it is painful to use these words) led to fostering a large number of talented people who will continue the Thurman school. If I could talk to Ron just once more, he would tell me that the human resources he fostered should also be included among his achievements.

I once asked Ron about the origin of the surname Thurman. He told me that his family was of German origin, and the original spelling, Türmann, meant 
"doorman." This could not be more fitting, as he led so many of his successors through the gates of scholarship, opening the way to their fascination with research. If he had lived a little longer, he would have certainly watched over our develop- ment. And with that, I close with deepest gratitude to Ron, beloved teacher to many Japanese researchers, and with admiration for his astounding achievements. 